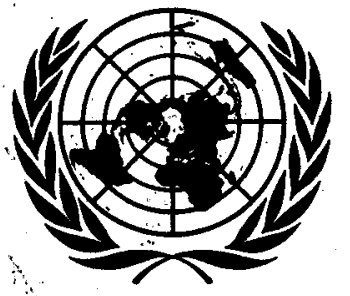

\title{
Second United Nations \\ International Conference \\ on the Peaceful Uses \\ of Atomic Energy
}

\author{
$\mathrm{A} / \mathrm{CONF} .15 / \mathrm{P} / 932$ \\ USA \\ 30 June 1958
}

ORIGINAL: ENGLISH

Confidential until official release during Conference

BÄSIC STUDIES OF THE SEPARATION OF URANIUM HEXAFLUORIDE FROM

MIXTURES CONTAINING CHLORINE TRIFLUORIDE AND

HYDROGEN FLUORIDE ${ }^{\mathrm{a}}$

H. A. Bernhardt, E. J. Barber, W. Davis; Jr. b; and R. M. McGill

Oak Ridge Gaseous Diffusion Plant

Union Carbide Nuclear Company

Oak Ridge, Teninessee

Processes for the conversion of uranium compounds or uranium metal to uranium hexafluoride ordinarily involve the use of a powerful fluorinating agent. Elemental fluorine is used when the scale of operations justifies the construction of a fluorine generating plant, but for smaller operations the use of the interhalogens of fluorine has definite advantages. These compounds: provide a high concentration of fluorihating power at moderate temperatures and pressures and are more easily stored and transported than fluorine. In addition, fluorinations in the liquid/phase often proceed more smoothly than those with gaseous fluorine. However, the use of the interhalogens introduces the problem of separating the uranium hexafluoride from the unreacted reagent and from any by-products which may, have been formed. The present work is concerried with the determination of the phase equilibria among the materials uranium hexafluoride, chlorine trifluoride, and hydrogen fluoride. This mixture occurs as a result of fluorinating uranium metal with chlorine trifluoride-hydrogen fluoride solutions or as a result of treating many uranium compounds and ores with chlorine trifluoride. These phase equilibria define the physical conditions necessary for separating the components by the processes of crystallization or distiliation and have, made possible the successful operation of a pilot plant for the direct recovery of uranium hexafluoride from spent metallic uranium fuel elements (1).

a. Others contributing to this work at the Oak Ridge Gaseous Diffusion Plant, Union Carbide Núcléar Company, were: . C. F. Hale, W. S. Wendolkowski, F. D. Rosen (present address, North American Aviation, Inc., Downey, California), R. L. Jarry (present address, Pennsalt Chemicals Corp., Philiadelphia, Pennsylvania), and G.. P. Rutledge (preșent address, Westinghouse Electric Corp., Atomic Power Department, Pittsburgh, Pennsylvania).

b. Present address, Union Carbide Nuclear Company, Oak Ridge National Laboratory, Oak Ridge, Tennessee. 


\section{DISCLAIMER}

This report was prepared as an account of work sponsored by an agency of the United States Government. Neither the United States Government nor any agency Thereof, nor any of their employees, makes any warranty, express or implied, or assumes any legal liability or responsibility for the accuracy, completeness, or usefulness of any information, apparatus, product, or process disclosed, or represents that its use would not infringe privately owned rights. Reference herein to any specific commercial product, process, or service by trade name, trademark, manufacturer, or otherwise does not necessarily constitute or imply its endorsement, recommendation, or favoring by the United States Government or any agency thereof. The views and opinions of authors expressed herein do not necessarily state or reflect those of the United States Government or any agency thereof. 


\section{DISCLAIMER}

Portions of this document may be illegible in electronic image products. Images are produced from the best available original document. 
The solid-liquid and liquid-vapor equilibria of the three binary systems were studied first; then the solid-liquid and liquid-liquid equilibria of the ternary system. The pure materials were prepared in the following manner.

Uranium Hexafluoride. Commercial uranium hexafluoride containing less than 0.015 weight per cent hydrogen fluoride was further purified by repeatedly bleeding the vapor from the molten compound. The final product had a sharp melting point of $64.04^{\circ} \mathrm{C}$. in good agreement with that reported for pure uranium hexafluoride (2).

Chlorine Trifluoride. Commercial chlorine trifluoride was passed as a vapor through a bed of sodium fluoride pellets and fractionally distilled in a nickel column having twenty theoretical plates. The product boiled at $+11.75^{\circ} \mathrm{C}$. at $760 \mathrm{~mm}$. pressure. The melting point was $-76.34^{\circ} \mathrm{C}$., corresponding to a purity of 99.96 per cent. Although this material was stored in well fluorinated nickel containers, sufficient decomposition occurred during a storage of about one month to require redistillation. Decomposition did not occur if the sample was stored at low temperature.

Hydrógen Fluoride. Commercial hydrogen fluoride was absorbed on a cooled bed of sodium fluoride pellets until the molar ratio of HF: NaF was about $1: 1$. Gaseous impurities were pumped off and the hydrogen fluoride evolved by heating the bed. This material was condensed in a container of cobalt trifluoride and allowed to desiccate for several hours. It was then transferred through a sintered metal filter to a dry, well fluorinated nickel container." The purity determined by measurement of the freezing point was 99.97 per cent.

\section{BINAPY SYSTEM URANIUM HEXAFLUORIDE-CHLORINE TRIFLUORIDE}

The solid-liquid equilibrium vas studied by means of a modification of the freezing-melting technique of skau. (3) Samples were contained in a thinwall welded nickel cylinder with a capacity of about $30 \mathrm{cc}$. equipped with a thermocouple well and a solenoid-driven stirrer. The sample cylinder was suspended inside a heavy cylindrical copper shield fitted with a thermocouple and a Nichrome heating element. The shield was placed in a large Dewar flask which could be immersed in liquid nitrogen or in a Dry Ice-trichloroethylene bath. The evacuation of the jacket of the Dewar flask was used as a control of the heat transfer rate Temperatures of the sample and the shield were measured with calibrated copper-constantan thermocouples and a White double potentiometer and are accurate to, $\pm 0.25^{\circ} \mathrm{C}$.

Mixtures were prepared by weighing the components accurately into thin nickel containers and transferring the contents to the stirred sample cylinder. The samples were cooled at the rate of $0.17^{\circ} \mathrm{C}$. per minute. Changes in the shield and sample temperatures are parallel until there is, a phase change in the sample. The sample temperature then falls more slowly until the eutectic temperature is reached. When the mixture has completely solidified at this temperature, the sample temperature again parallels the shield temperature.

From a family of these warming-freezing curves, the phase diagram for the system uranium hexafluoride-chlorine trifluoride was obtained as shown in 


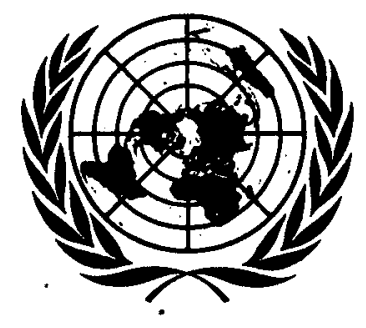

Second United Nations

International Conference

on the Peaceful Uses

of Atomic Energy

$A / C O N F .15 / P / 932$

Abstract (USA)

10 March 1958

ORIGINAL: ENGLISH

Confidential until official release during Conference

BASIC STUDIES OF THE SEPARATION OF URANIUM HEXAFLUORIDE FROM

MIXTURES CONTAINING CHLORINE TRIFLUORIDE AND HYDROGEN FLUORIDE

Prepared by

$\frac{\text { R.M. McGill, E. J. Barber, W. Davis, Jr., H. A. Bernhardt* }}{\text { Oak Ridge Gaseous Diffusion Plant }}$
Union Carbide Nuclear Company
Oak Ridge, Tennessee

Abstract

The problem of separating uranium hexafluoride from mixtures containing chlorine trifluoride and/or hydrogen fluoride arises as a consequence of the fluorination of uranium ores, uranium tetrafluoride, or spent reactor fuel elements with chlorine trifluoride. The phase equilibria, which determine the conditions for the separation of the components, were studied first for the three binary systems, then for the condensed ternary system. These data aided in the successful operation of a pilot plant for the direct recovery of uranium hexafluoride from spent metallic uranium fuel elements.

Binary System: Uranium Hexafluoride-Chlorine Trifluoride. The solid-liquid equilibrium was studied by means of a modification of the freezing-melting technique of Skau. The system is simple and exhibits small positive deviations from Raoult's law. The single binary eutectic contains 0.4 mole percent uranium hexafluoride and melts at $-77.4{ }^{\circ} \mathrm{C}$. Enantiotropy of the solid chlorine trifluoride was observed at $-83.1^{\circ} \mathrm{C}$.

The liquid-vapor equilibrium was studied at total pressures of $1.5,2.0,2.5$, and 3.0 atmospheres. The system is a simple zeotropic one, but at pressures below 2.5 atmospheres the liquidus curves intersect the solubility curve, resulting in the deposition of a solid phase. No evidence of compound formation was observed even at higher pressures.

Binary System: Uranium Hexafluoride-Hydrogen Fluoride。. The solid-liquid equilibrium shows large positive deviations from ideality. Between 10 and 80 formula percent uranium hexafluoride and above $61.2^{\circ} \mathrm{C}$. the components form two immiscible liquid phases with a consolute temperature of $101^{\circ} \mathrm{C}$. The single binary eutectic freezes at $-85^{\circ} \mathrm{C}$.

The presence of the miscibility gap and the polymeric nature of hydrogen fluoride greatly complicate the liquid-vapor equilibria. An azeotrope does exist, containing 80 to 85 formula percent hydrogen fluoride, the exact composition being temperature dependent.

Binary System: Chlorine Trifluoride-Hydrogen Fluoride. The solid-liquid equilibrium shows large positive deviations from ideality. The single binary

*Including work by G. P. Rutledge, C. F. Hale, R. L. Jarry, F。D. Rosen, and W. S. Wendolkowski. 
Basic Studies of the Separation of Urantum Hexafluoride from Mixtures Containing Chlorine Trifluoride and Hydrogen Fluoride - McGill, Barber, Davis, Bernhardt

Page 2 .

eutectic contains 7.5 formula percent chlorine trifluoride and melts at $-88.8^{\circ} \mathrm{C}$. The solubility data involve both of the crystalline forms of chlorine trifluoride.

The liquid-vapor equilibria show the existence of an azeotrope contalning about 67 formula percent chlorine trifluoride; however, the strong positive deviations from ideality suggest that the azeotrope is not an intermolecular compound.

Condensed Phase Ternary System. The solld-liquid and liquid-liquid solubility data given above were combined with ternary solubility data to obtain the solubility surfaces for the ternary system. The ternary eutectic temperature was found at $-91^{\circ} \mathrm{C}$, the composition being 19.5 formula percent chlorine trifluoride, 80.5 formula percent hydrogen fluoride, and less than 0.2 formula percent uranium hexafluoride. Adaition of chlorine trifluoride to mixtures of the other two components suppresses the misciblilty gap; the minigap temperature occurs at $53^{\circ} \mathrm{C}$. at a composition of 49 formula percent uranium hexafluoride, 13 formula percent chlorine trifluoride and 38 formula percent hydrogen fluorlde. The ternary liquid-vapor equilibria were not determined.

The above data show that uranium hexafluoride may be separated with high efficiency from either the binary or ternary mixtures by freezing. Fractional distillation is also practical, though less attractive because of the presence of the uranium hexafluoride-hydrogen fluoride azeotropes. 


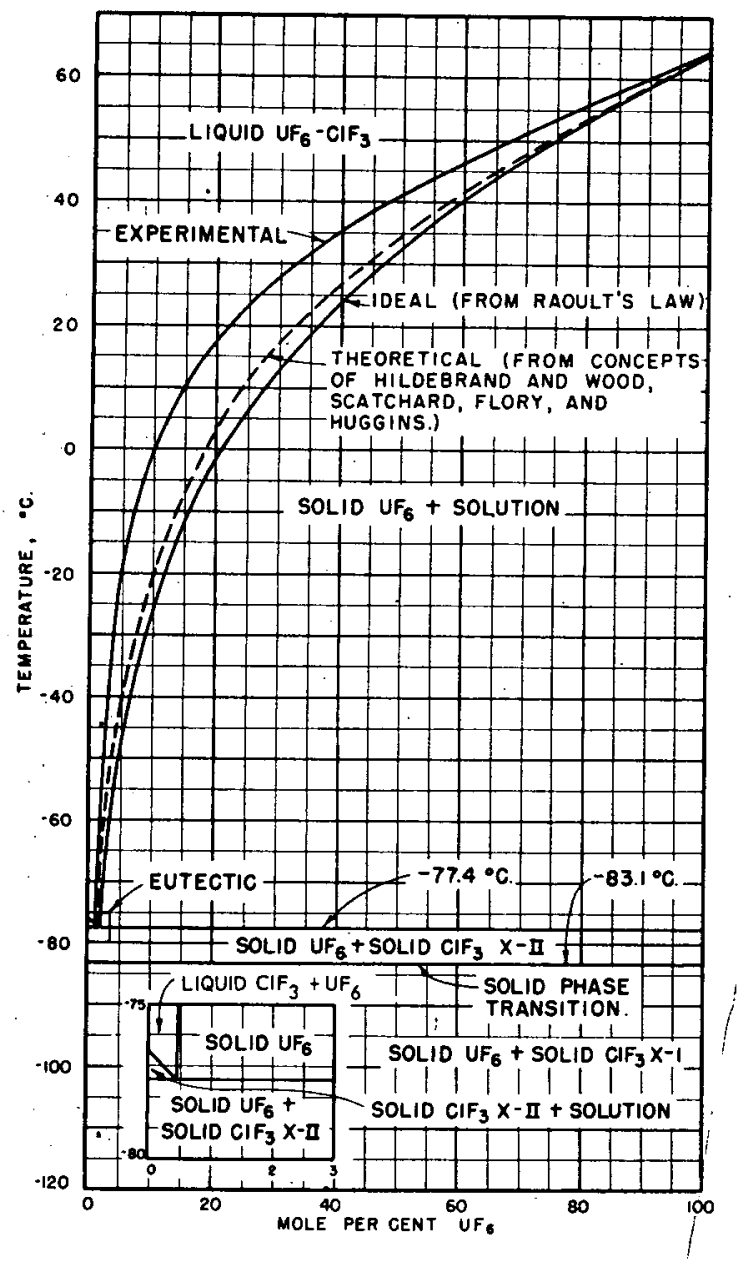

SOLID-LIQUID PHASE DIAGRAM CHLORINE TRIFLUORIDE-URANIUM HEXAFLUORIDE

Figure 1
Figure 1. The system is a simple one with a single binary eutectic containing about 0.4 mole per cent uranium hexafluoride and freezing at $-77.4^{\circ} \mathrm{C}$. There was no evidence of compound formation. At a temperature of $-83.1^{\circ} \mathrm{C}$. the solid chlorine trifluoride undergoes an enantiotropic transformation.

The liquid-vapor equilibria of this system were studied with a nickel othmer-type equilibrium still consisting of a simple vacuum-jacketed boiler and a condenser. Provisions were made for recycling the condensate to the boiler and for sampling the liquid in the boiler and the condensate. Synthetic mixtures of the components of about $25 \mathrm{cc}$. were charged to the still and allowed to circulate for six hours to attain equilibrium at constant pressure. The temperature was then measured and I cc. liquid samples withdrawn from the boiler and condenser. The samples were hydrolyzed with water in a jet and analyzed for the ratio uranium/chlorine. The compositions determined in this manner are accurate to within \pm 2 per cent.

The data are presented in Figure 2 for total pressures of $1.5,2.0,2.5$, and 3.0 atmospheres absolute. At distillation pressures up to 2.5 atmospheres, the liquidus curves intersect the solubility line for this system resulting in the deposition of solid uranium/hexafluoride in the boiler. The system then becomes invariant and distills at constant composition. This difficulty is not encountered above 2.5 atmospheres pressure, and the components may be completely separated by fractionali distillation. There was no evidence of compound formation even in tests at higher pressures:

\section{BINARY SYSTEM CHLORINE TRIFLUORIDE-HYDROGEN FLUORIDE}

The solid-liquid equilibrium were determined with the same apparatus described above. The data are presented in Figure 3. These components form a 


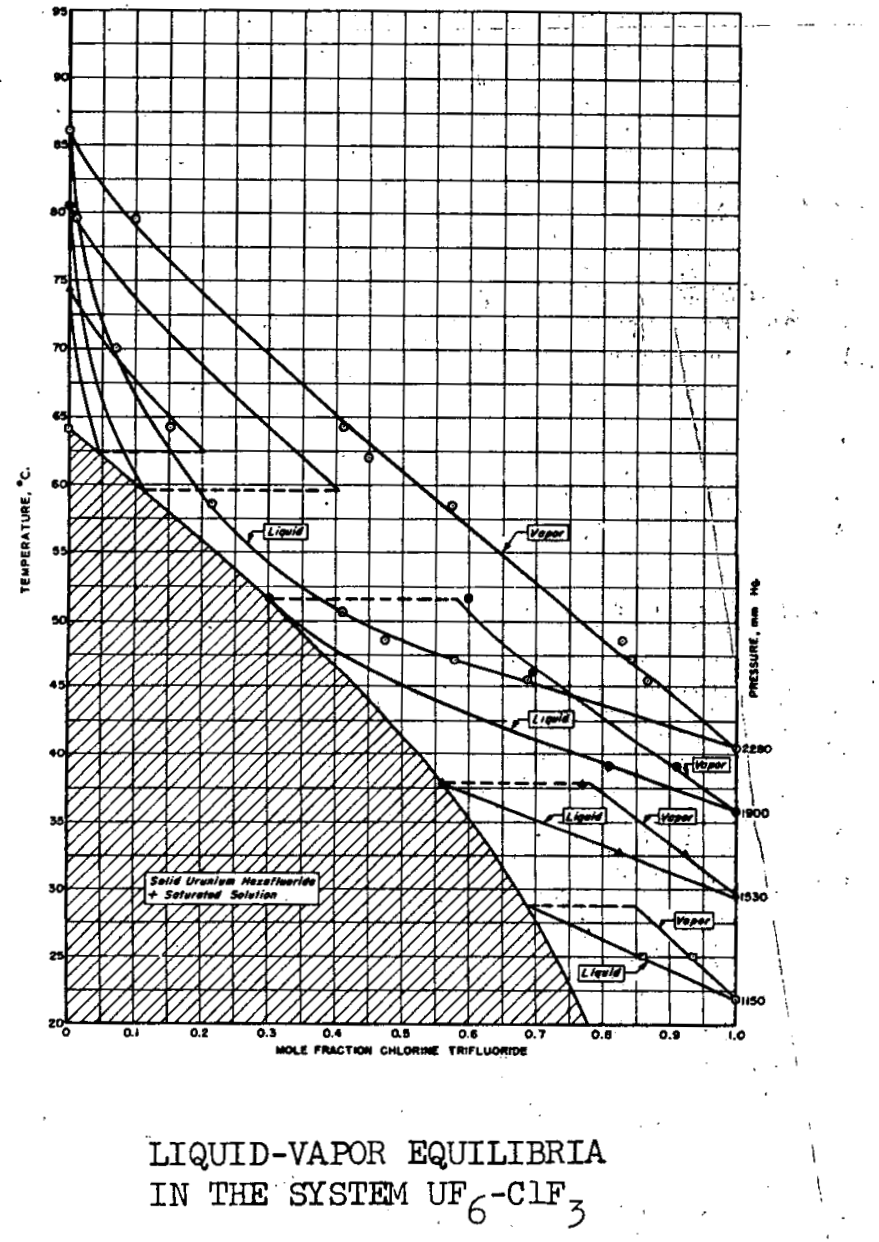

Figure 2 simple system with a single binary eutectic containing 7.5 formula per cent chlorine trifluoride and freezing at $-88.8^{\circ} \mathrm{C}$. The necessity of expressing the concentration in formula per cent arises because of the unknown degree of association of hydrogen fluoride which makes its actual molar concentration indefinite, The two crystalline forms of chlorine trifluoride exhibit different solubilities in hydrogen fluoride as shown in the figure. Large positive deviations from Raoult's law were observed, but there was no evidence of a miscibility gap or of the formation of a compound.

The liquid-vapor equilibria were determined with the same equilibrium still described for the previous system. The equilibrium samples were analyzed by vaporizing them slowly through a tared, well fluorinated trap of sodium fluoride pellets and taking the weight gain of the trap as the weight of hydrogen fluoride. From the weight of the initial sample, the composition of the mixture

could be calculated. Results were accurate to \pm 0.5 formula per cent.

The data are presented in Figure 4 for total pressures of $1.5,2.0,2.5,3.0$, and 4.0 atmospheres absolute. This system contains a minimum boiling azeotrope whose composition is not sensitive to pressure. The azeotrope contains about 67 formula per cent chlorine trifluoride, but the proximity of this composition to that of a compound $\mathrm{HF} \cdot 2 \mathrm{ClF}_{3}$ must be consider ed fortuituous. While the compound $\mathrm{HF} \cdot \mathrm{ClF}_{3}$ has been identified in the vapor state at subatmospheric pressures (4), the strong positive deviations from Raoult's law which were observed are not consistent with a complexed system. The freezing point data for this system also gave no indication of such a compound.

\section{BINARY SYSTEM URANIUM HEXAFLUORIDE-HYDRंOGEN FLUORIDE}

For concentiations of uranium herafluoride in hydrogen fluoride up to 10 
formula per cent, the freezing point apparatus previously described was used. Above this concentration, the components separate into two immiscible solutions, and it vas necessary to determine visually the temperature requirea to form a single homogeneous liquia phase. Transparent fluorothene tubes containing synthetic mixtures of the components were slowly warmed and shaken until a clear solution resulted. The temperatures so obtained are only correct to $\pm 2^{\circ} \mathrm{C}$.

The solid-liquid equilibrium data are presented in Figure 5. The miscibility gap begins at $61.2^{\circ} \mathrm{C}$. and extends over the composition range of $10 \pm 0.5$ to $80 \pm 3$ formula per cent uranium hexafluoride. The consolute temperature for this system is $101^{\circ} \mathrm{C}$. A single binary. eutectic freezes at $-85^{\circ} \mathrm{C}$. and contains less than 0.5 formula per cent uranium hexafluoride. There was no evidence of compound formation.

The presence of the miscibility gap just described made it necessary to use a different apparatus for investigating the liquid-vapor equilibria. A sealed magnetic pump was used to circulate the vapor phase through a vapor flask and then back through the liquid phase until equilibrium had been attained at constant temperature and pressure. The vapor flask was isolated and the contents transferred to a thin nickel vapor density bulb under measured conditions. From the vapor density, the composition of the vapor could be calculated. A similar analysis was made of the liquid phase by completely vaporizing a small liquid sample into the bulb. This method of analysis was checked with several gases and gave good results. Similar runs were made at several different temperatures and with different mixtures of the components in the liquid container. The results are presented in Figure 6. The minimum boiling azeotrope contains 15 to 20 formula per cent uranium hexafluoride depending upon the total pressure. The shape of the : diagram illustrates the ease of purifying uranium hexafluoride from small amounts of hydrogen fluoride by distillation.

\section{CONDENSED PHASE TERNARY SYSTEM}

The solid-liquid equilibria for the three binary systems just described were used as a basic for constructing the solubility surfaces for the ternary system. Additional data on the freezing point and miscibility limits of synthetic mixtures of the three components were obtained by observing their behavior on warming and cooling in transparent fluorothene tubes. Particular attention was given to determining the changes in the uranium hexafluoridehydrogen fluoride miscibility gap on adding chlorine trifluoride.

The results are sumarized in Figure 7 . The addition of chlorine trifluoride to mixtires of the other two components suppresses the miscibility gap. It disappears completely at a composition of 49 formula per cent uranium hexafluoride; 38 formula per cent hydrogen fluoride, and 13 formula per cent. chlorine trifluoride. The corresponding temperature, the so-called minigap temperature, is $53^{\circ} \mathrm{C}$. A single ternary eutectic occurs at $-91^{\circ} \mathrm{C}$. containing 19.5 formula per cent chlorine trifluoride, 80.5 formula per cent hydrogen fluoride, and less than 0.2 formula per cent uranium hexafluoride. 


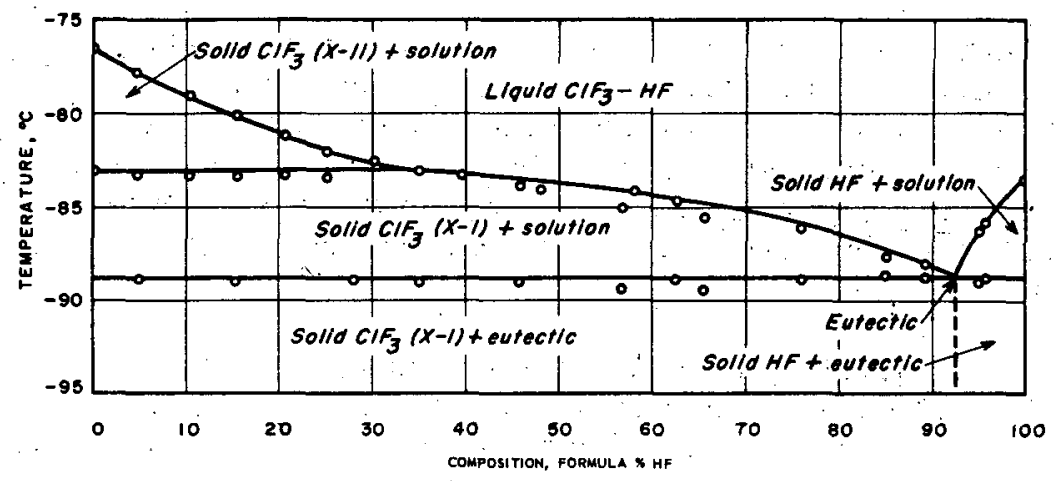

SOLID-ITQUID EQUILIBRIUM OF THE SYSTEM CHLORINE TRIFLUORIDE-HYDROGEN FLUORIDE

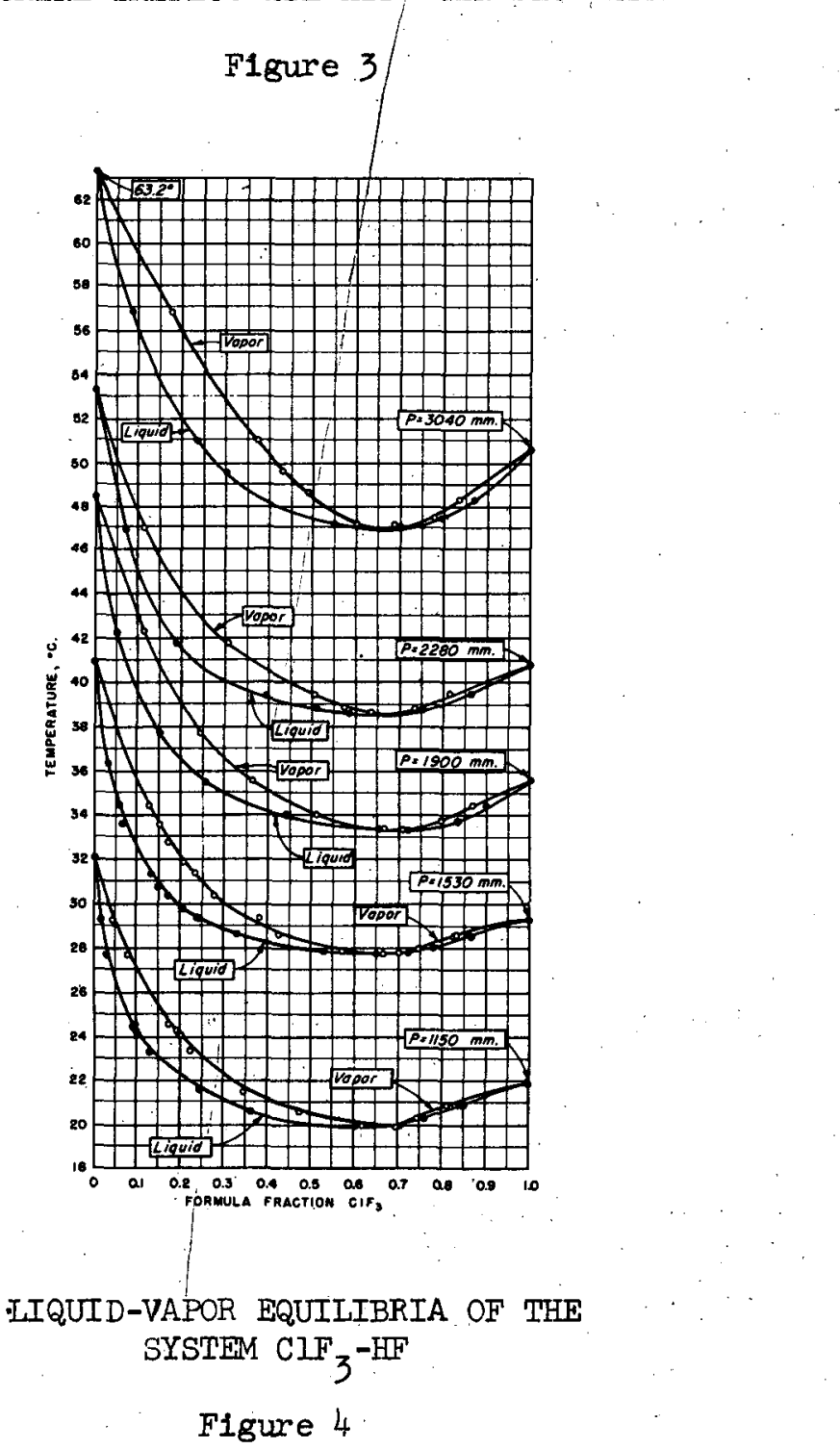






Figure 5 


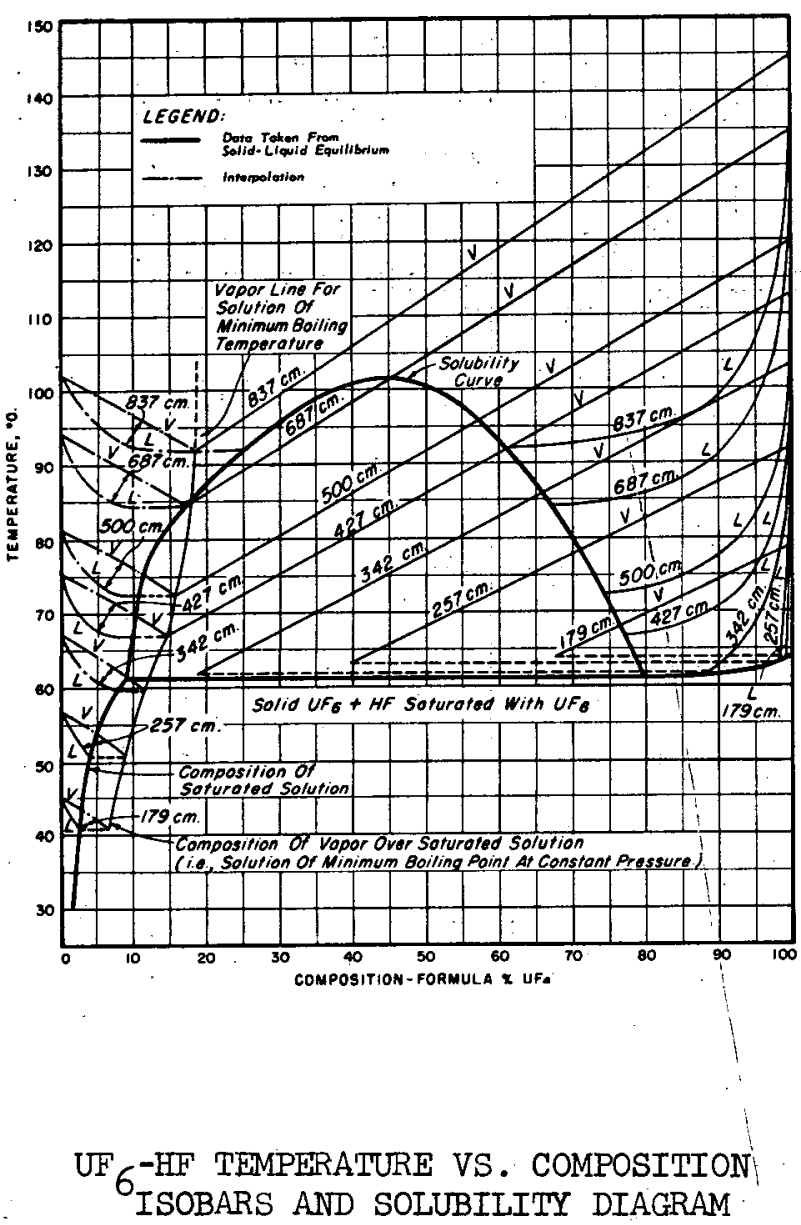

Figure 6

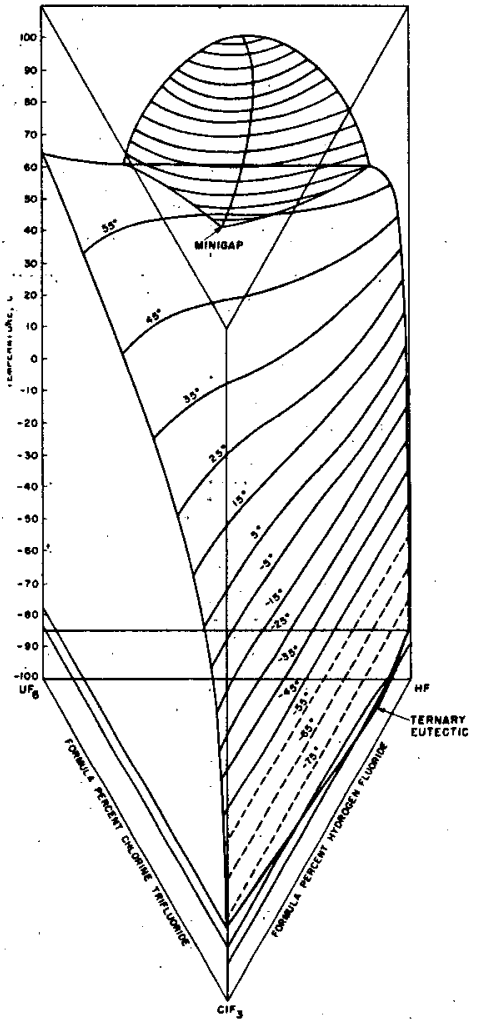

TEMPERATURE/COMPOSITION PRISM FOR THE CONDENSED SYSTEM UF $6^{-\mathrm{HF}-\mathrm{ClF}} 3$

Figure 7

Determination of the liquid-vapor equilibria of the ternary system was not undertaken since the presence of the miscibility. gap would make such a task extremely complex. These data were also considered unnecessary since the binary and condensed phase ternary systems offer efficient methods of separating pure uranium hexafluoride. The most outstanding feature of these systems is the very small amount of uranium hexafluoride contained in the binary and ternary eutectics, suggesting that crystallization processes should separate uranium hexafluoride in high yield. Distillation methods are complicated by the presence of the uranium hexafluoride-hydrogen fluoride azeotrope, but if the uranium content of a mixture were first highly enriched by crystallization, the residual impurities would be readily removed by simple refluxing. 


\section{BIBLIOGRAPHY}

1. Bernhardt, H. A., Barber, E J., and Gustison, R. A., Basic Chemical Aspects of the Chlorine Trifluoride Process for the Recovery of Irradiated Uranium, Presented at the Nuclear Technology Symposium, Spring Meeting of the American Chemical Society, San Francisco, April 1958.

2. Oliver, G. D., Milton, H. T., and Grisard, J. W., The Vapor Pressure and Critical Constants of Uranium Hexafluoride, J. Am Chem. Soc., 75:2827, (1953).

3. Skau, E. L., Purification and Physical Properties of Organic Compounds. I. The Interpretation of Time-Temperature Curves in Freezing-Point Determinations and as a Criterion of Purity, Proc. Am. Acad. Arts Sci., 67:551, (1933).

4. Pemsler, J. P. and Smith, D. F., An Infrared Band of a Molecular Complex Between Eydrogen Fluoride and Chlorine Trifluoride, J. Chem. Phys., $22: 1834,(1954)$.

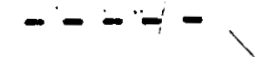

